\title{
Anodic Nanoporous Niobium Oxide Layers Grown in Pure Molten Ortho-Phosphoric Acid
}

\author{
Marco Altomare, ${ }^{a *}$ Gihoon Cha, ${ }^{a}$ Patrik Schmuki ${ }^{\mathrm{a}, \mathrm{b}}$ \\ a Institute for Surface Science and Corrosion WW4-LKO, Department of Materials Science and \\ Engineering, University of Erlangen-Nuremberg, Martensstrasse 7, 91058 Erlangen, Germany \\ b Chemistry Department, Faculty of Sciences, King Abdulaziz University, 80203 Jeddah, \\ Kingdom of Saudi Arabia \\ * Corresponding author. E-mail: marco.altomare@fau.de
}

Link to the published article:

https://www.sciencedirect.com/science/article/pii/S0013468620305508 


\begin{abstract}
The anodic oxidation of niobium is investigated in pure molten ortho-phosphoric acid $\left(\mathrm{o}-\mathrm{H}_{3} \mathrm{PO}_{4}\right)$. At applied potentials in the $2.5-60 \mathrm{~V}$ range and for electrolyte temperatures in the $60-110^{\circ} \mathrm{C}$ range, porous niobium oxide layers are formed. Pore ordering and morphology depend on the anodization voltage, time and temperature, i.e. the anodic oxide develops different morphologies depending on low- or high-field anodizing conditions. At $100^{\circ} \mathrm{C}$ and low voltages, e.g. $\leq 5 \mathrm{~V}$, vertically oriented, amorphous oxide nanopores with cylindrical shape ("nanochannels") grow with an average diameter of 5-8 $\mathrm{nm}$. Higher voltages (10-20 V) lead to a less ordered pore morphology, resembling a "fish bone" structure. At 40-60 V, and after a sufficiently long anodization time ( $\geq 30 \mathrm{~min}$ ), an orthorhombic $\mathrm{Nb}_{2} \mathrm{O}_{5}$ hierarchical structure forms that shows a bimodal pore size distribution with some $100 \mathrm{~nm}$ wide main pores that branch out into $\sim 10 \mathrm{~nm}$ sized nanochannels. A partial crystallization of the anodic oxide is observed at high voltages $(\geq$ $40 \mathrm{~V})$. We propose that this is due to a high field-induced crystallite nucleation in the barrier oxide at the oxide/metal interface. With time, the crystalline oxide is incorporated in the porous layer. The main pores, partially crystalline and hence more stable in the anodizing electrolyte, result from the gradual dissolution of the amorphous side nanochannels.
\end{abstract}

Keywords: Porous niobium oxide; Anodization; Self-organizing electrochemistry; Orthophosphoric acid; High field induced crystallization 


\section{Introduction}

Defined one-dimensional (1D) metal oxide nanostructures are receiving nowadays a great deal of attention because of their manifold potential technological applications. They provide a set of intriguing features, such as high surface area, large porosity, and advanced optical or charge transport properties.

Several 1D metal oxides, e.g. Ti, Al, Zr, Hf, Fe, W, V, Co and Ta among others (see for an overview ref. [1] and refs. therein), can be grown by anodic oxidation of their parent metals under self-organizing electrochemical conditions. This is valid also for $1 \mathrm{D} \mathrm{Nb}$ oxide nanostructures, which can find wide application in gas sensing, electrochromic devices, catalysis, solar energy conversion and energy storage, e.g. as anode material for batteries and supercapacitors.

The anodic growth of $1 \mathrm{D} \mathrm{Nb}$ oxide nanostructures has been reported to occur in different electrolytes and was pioneered by $\mathrm{Lu}$ et al. [2] and Sieber et al. [3], who reported on the anodization of niobium in a hot glycerol/phosphate medium or in mixed $\mathrm{H}_{2} \mathrm{SO}_{4} / \mathrm{HF}$ aqueous electrolytes. In early work however, only some porous, comparably short and undefined morphologies could be formed.

Various studies have then followed up, such as those of Choi et al. [4] and Wei et al. [5], who explored diluted $\mathrm{HF} / \mathrm{H}_{3} \mathrm{PO}_{4}$ aqueous electrolytes or $\mathrm{NH}_{4} \mathrm{~F} /$ glycerol mixtures. Among these reports, most relevant to the present study is previous work on anodizing in hot phosphate containing electrolytes. The formation of tens of micrometers thick, porous anodic oxide layers was in fact reported for $\mathrm{Nb}$ as well as for $\mathrm{Al}$, Ta, $\mathrm{Ti}$ and $\mathrm{Ti}$ alloys in hot glycerol electrolytes containing $\mathrm{K}_{2} \mathrm{HPO}_{4}[2,6]$ (although initially such anodic layers were considered to be of a barriertype [7]). Particularly, a reduced water concentration in the organic electrolyte was found to be key for the growth of porous anodic niobium oxide [8]. Despite the small water amounts required for the growth, SIMS depth profiles of porous $\mathrm{Nb}$ oxide formed in electrolytes with $\mathrm{H}_{2}{ }^{18} \mathrm{O}$ 
enrichment have revealed that the oxide ions in the anodic layers originate from the water impurity in the electrolyte $[8,9]$.

More recently, we reported on a (nominally) water-free electrolyte based on molten pure orthophosphoric acid $\left(\mathrm{o}-\mathrm{H}_{3} \mathrm{PO}_{4}\right)$. We found that this anodizing medium enables the formation of highly ordered, high aspect ratio $1 \mathrm{D}$ oxide structures on various valve metals such as $\mathrm{W}, \mathrm{Nb}$ or $\mathrm{Al}$ [10-12]. These porous anodic layers adhere excellently on the substrate and exhibit high regularity.

We investigated for $\mathrm{W}$ oxide the effects of key anodizing parameters and found that essential to the growth of high aspect-ratio anodic layers is the water content. When molten $\mathrm{o}-\mathrm{H}_{3} \mathrm{PO}_{4}$ is used as anodizing medium, the key oxidant is remnant of water, as such electrolyte is sufficiently hygroscopic to maintain a certain water level even at high temperatures. Karl Fischer analysis demonstrated that the water content of pure $\mathrm{o}-\mathrm{H}_{3} \mathrm{PO}_{4}$, molten and heated up to $100^{\circ} \mathrm{C}$ is of approximately $1.1 \%$ [10]. When adding increasing amounts of water to the pure molten electrolyte, only comparably undefined $\mathrm{WO}_{3}$ structured could be produced.

In the present work we explore in detail the development of anodic $\mathrm{Nb}$ oxide layers in pure molten $\mathrm{o}-\mathrm{H}_{3} \mathrm{PO}_{4}$. We investigate the anodic growth mechanism and its dependence on parameters such as anodizing voltage, time and electrolyte temperature. We show that while nanoporous $\mathrm{Nb}$ oxides grow under a wide range of electrochemical conditions, morphology, crystallinity and chemical composition of the anodic layers are substantially affected by the applied field strength. We identified different growth regimes, i.e. low and high field mechanisms, and relative sets of anodizing conditions. 


\section{Experimental Section}

The anodic $\mathrm{Nb}$ oxide layers were grown by anodic oxidation of $\mathrm{Nb}$ metal substrates in pure molten ortho-phosphoric acid $\left(\mathrm{o}-\mathrm{H}_{3} \mathrm{PO}_{4}\right)[10,12]$. $\mathrm{Nb}$ foils $(0.125 \mathrm{~mm}, 99.9 \%$ purity, Advent Research Materials LTD, Oxford, UK) were cut into 1 x $2 \mathrm{~cm}^{2}$ pieces, cleaned by ultra-sonication in acetone, ethanol and de-ionized water (10 min each), and then dried in a $\mathrm{N}_{2}$ stream.

For the anodization experiment, a two-electrode electrochemical cell was used, where the $\mathrm{Nb}$ and Pt foils were the working and counter electrodes, respectively. The two electrodes were immersed into the electrolyte in a vertical configuration and were placed at a distance of $2 \mathrm{~cm}$ from each other.

The electrolyte was prepared by melting at temperatures $>\sim 50^{\circ} \mathrm{C}$ pure o- $\mathrm{H}_{3} \mathrm{PO}_{4}(99 \%$, Emsure; white solid at room temperature). During the anodization experiments, the molten acid electrolyte was constantly stirred and kept at the desired temperature by thermostatic control $\left(60-120^{\circ} \mathrm{C}\right)$.

The experiments were performed under potentiostatic conditions, i.e. by applying a constant anodic bias in the 2.5-60 V range) provided by a Volcraft VLP 2403 Pro power supply. The anodic current density (J) was recorded by using a Keithley 21006 1/2 Digit multimeter. The typical duration of the anodization experiments was $1 \mathrm{~h}$. After anodization, the anodic layers were rinsed with water, dried with a $\mathrm{N}_{2}$ stream and characterized in view of their morphological and physicochemical features.

A Hitachi field emission scanning electron microscope (FE-SEM S4800, Hitachi) was used for the top surface and cross-sectional morphological characterization of the anodic oxides. X-ray diffraction (XRD) patterns were collected using an X'pert Philips PMD diffractometer with a Panalytical X'celerator detector, using graphite-monochromized $\mathrm{Cu} \mathrm{K} \alpha$ radiation $(\lambda=1.54056$ $\AA$ ). The chemical composition of the anodic layers was determined by X-ray photoelectron spectroscopy (XPS, PHI 5600, US). XPS spectra were acquired using monochromatic Al X-ray 
source with a pass energy of $23.5 \mathrm{eV}$. The XPS spectra were corrected in relation to the $\mathrm{C} 1 \mathrm{~s}$ signal at $284.8 \mathrm{eV}$. PHI MultiPak ${ }^{\mathrm{TM}}$ software and database were used for quantitative analysis.

\section{Results and Discussion}

In a first series of experiments we explored the effect of the applied voltage (2.5-60 $\mathrm{V}$ range) on the structure of anodic $\mathrm{Nb}$ oxide layers grown in pure molten $\mathrm{o}-\mathrm{H}_{3} \mathrm{PO}_{4}$ at $100^{\circ} \mathrm{C}$ (anodization time: 1 h). Top view and cross-sectional SEM images of the resulting structures are shown in Fig. 1-3. Independent of the anodizing voltage, the layer morphologies closely resemble that of the well-known porous anodic alumina produced in aqueous acid electrolytes, i.e. an upper layer consisting of metal oxide nanopores (Fig. 1 and 2) is developed above an oxide barrier layer that separates the porous oxide from the metal substrate (Fig. 3).

Structures formed at voltages $\leq 10 \mathrm{~V}$ show defined pore openings at the oxide top surface (Fig. 1), while higher electric fields ( $U \geq 20 \mathrm{~V}$ ) seem to cause a partial etching of the topmost part of the anodic layer. The average pore diameter at the oxide surface increases with the anodizing voltage, and is e.g. 5-6, 15-20 and 25-40 nm for structures grown at 2.5, 10 and $60 \mathrm{~V}$, respectively.

More pronounced differences can be appreciated from the cross-sectional SEM images in Fig. 2 and 3, as well as from the data in Fig. 4 where the J-time characteristics and porous anodic layer and barrier oxide thickness are reported as a function of the anodizing voltage.

Pore ordering and layer morphology strongly depend on the applied electric field. At voltages $\leq$ $20 \mathrm{~V}$, the J-time curves resemble each other (Fig. 4a), featuring an initial steep increase of the anodic current density, which then rapidly decreases and reaches steady state values within the first 5 minutes of anodization. The current density values in the steady state regime increase with increasing the applied voltage. Steady-state $\mathrm{J}$ values are $\sim 0.1$ and $0.7 \mathrm{~mA} \mathrm{~cm}^{-2}$ at 2.5 or $20 \mathrm{~V}$, 
respectively. At 2.5 or $5 \mathrm{~V}$, vertically oriented cylindrical nanopores ("nanochannels") grow with an average diameter of $\sim 5-8 \mathrm{~nm}$. Higher voltages $(10-20 \mathrm{~V})$ lead to a lower pore ordering and to a less defined oxide morphology that resembles a "fish bone" structure with average channel diameter of $\sim 10 \mathrm{~nm}$ (Fig. 2), i.e. in contrast to those formed at 2.5-5 V, such nanopores do not grow normal to the metal substrate surface.

In general, the facts that the minimum current density tends to increase with increasing the formation voltage and the presence of a current minimum in the current transients resemble what has been observed for the formation of porous anodic alumina in aqueous acidic electrolytes. The gradual current decrease after the current maximum at the formation voltages of 2.5 to $20 \mathrm{~V}$ is associated with a diffusion-controlled reaction process.

Substantial morphological changes occur when anodizing at voltages $\geq 40 \mathrm{~V}$ (Fig. 2). Evident differences can also be appreciated from the relative J-time curves compared to those recorded at lower voltages (Fig. 4a). At $40 \mathrm{~V}$, the current density levels off at a steady state value of $0.5 \mathrm{~mA}$ $\mathrm{cm}^{-2}$ within the first 30 minutes of anodization and then gradually increases up to $\sim 1 \mathrm{~mA} \mathrm{~cm}$. At $60 \mathrm{~V}$, the current density increase from the steady state regime (in this case $\sim 1 \mathrm{~mA} \mathrm{~cm}{ }^{-2}$ ) is even more significant, as it reaches after $1 \mathrm{~h} \mathrm{~J}$ values as high as $\sim 2 \mathrm{~mA} \mathrm{~cm}^{-2}$. At 40-60 V we observe the formation of $\mathrm{Nb}$ oxide hierarchical structures (Fig. 2), which show a bimodal pore size distribution, with some $100 \mathrm{~nm}$ wide main pores that branch out into $\sim 10 \mathrm{~nm}$ sized nanochannels. The side nanochannels (branches) are more evident at the top of the anodic layers, while the $\sim 100 \mathrm{~nm}$ sized nanopores are well defined towards the oxide/metal interface and feature smooth side walls particularly at $60 \mathrm{~V}$.

The increase of the voltage leads also to a thickening of the anodic layers (Fig. 4b). At voltages in the 2.5-20 $\mathrm{V}$ range, the anodic layers grow with an average rate of $\sim 57 \mathrm{~nm} \mathrm{~V}^{-1}$, while at voltage $\geq 20 \mathrm{~V}$ the growth slows down to $5 \mathrm{~nm} \mathrm{~V}^{-1}$. At any voltage, a barrier layer underneath the porous 
oxide is formed (insets in Fig. 3), which thickens in proportion to the formation voltage at a ratio of $3.8 \mathrm{~nm} \mathrm{~V} \mathrm{~V}^{-1}$ (Fig. 4c). The thickness of the barrier layer increases also with increasing the electrolyte temperature (discussed below).

The decline in growth rate indicates that, compared to porous layers grown at $2.5-20 \mathrm{~V}$, a more pronounced chemical dissolution of the anodic films occurs when anodizing at higher voltages. This is in line with the comparably higher current densities observed at higher voltages, which can cause partial dissolution of the topmost part of the anodic layers. This is clear from the top view SEM images in Fig. 1.

In our previous work [12], we found the structures grown at $5 \mathrm{~V}$ to be amorphous, while their crystallization into orthorhombic $\mathrm{Nb}_{2} \mathrm{O}_{5}$ could be achieved by annealing in air at temperatures $\geq$ $350^{\circ} \mathrm{C}$. As-formed layers were mainly composed of $\mathrm{Nb}, \mathrm{O}, \mathrm{P}$ (from the anodizing electrolyte) and $\mathrm{C}$ (adventitious). The Nb:O surface content ratio (determined by XPS analysis) was found to be 0.3, hence slightly lower than that expected for stoichiometric $\mathrm{Nb}_{2} \mathrm{O}_{5}$ (i.e. 0.40). Also, XPS analyses showed the presence of a peak at $134.3 \mathrm{eV}$, i.e. due to the $\mathrm{P} 2 \mathrm{p}$ signal, that indicated the presence at the anodic oxide surface of phosphates or similar $\mathrm{P}$ species. The surface $\mathrm{P}$ content, ca. 6 at $\%$ for layers grown at $5 \mathrm{~V}$ for $5 \mathrm{~h}$, did not vary significantly upon annealing. The relatively high $\mathrm{P}$ content is in contrast with what reported by Oikawa et al., who observed a negligible incorporation of phosphorus species in porous anodic $\mathrm{Nb}$ oxide grown in hot phosphate-glycerol electrolytes [13].

Moreover, in the present work, we observed that when anodizing in pure molten $\mathrm{o}-\mathrm{H}_{3} \mathrm{PO}_{4}$, the voltage can substantially affect not only the oxide morphology and chemical composition but also the crystallinity of the anodic layers. As discussed below, the nucleation of crystalline oxide in the anodic layers formed at high voltages is proposed as the main cause for their different 
morphologies, i.e. the development of the niobium oxide structure should be associated with nonuniform chemical dissolution of the anodic film during anodizing.

The XRD patterns and surface phosphorous content (determined by XPS analysis) for anodic layers formed in pure $\mathrm{o}-\mathrm{H}_{3} \mathrm{PO}_{4}$, at $100^{\circ} \mathrm{C}$ at different anodizing voltage $(2.5-60 \mathrm{~V}$ range; anodization time: $1 \mathrm{~h}$ ) are compiled in Fig. 5. The XRD patterns in Fig. 5a show that the asformed layers grown at low voltages are amorphous and only reflections ascribed to the $\mathrm{Nb}$ metal substrate can be seen. Such diffraction peaks at $38.5,55.7$ and $69.8^{\circ}$ can be assigned to the (110), (200) and (211) planes of metal $\mathrm{Nb}$ cubic phase. However, crystalline (orthorhombic) $\mathrm{Nb}_{2} \mathrm{O}_{5}$ phase is detected in the as-formed anodic oxides grown at 40 and $60 \mathrm{~V}$, and the higher the voltage the more pronounced the diffraction peak at $\sim 28.6^{\circ}$. The diffraction peak at $\sim 28.6^{\circ}$ can be assigned to the (180), (200) and (110) planes of orthorhombic $\mathrm{Nb}_{2} \mathrm{O}_{5}$ phase. The results suggest that nucleation and growth of crystalline oxide are accelerated by increasing the applied potential [14], i.e. the growth at $60 \mathrm{~V}$ causes the incorporation of larger amounts of crystalline oxide in the anodic layer.

The morphological and crystallographic changes observed with increasing the anodizing voltage are also accompanied by a gradually increasing uptake of phosphorous from the anodizing electrolyte, as illustrated in Fig. 4b. Similar results have been observed also for anodic alumina [15-18] or tantala [19], where the total amount and depth of incorporated phosphorus species were found to increase with increasing current density (and decreasing electrolyte temperature), i.e. scaling with the strength of the applied electric field. Besides, incorporation of carbon species was reported in anodic porous iron oxide [19] or titania [1,20] grown in organic electrolytes.

Field induced crystallization has been observed for different barrier-type anodic oxides of e.g. niobium or tantalum, grown in aqueous solutions. The nucleation of crystalline oxide is reported to take place only in the barrier oxide as during oxide growth, the high electric field applies to the 
barrier layer, but not to the porous oxide layer. It has also been reported that microcones of anodic niobium oxide consisting of branched nanofibers can be formed in hot phosphate-glycerol electrolytes due to (i) the crystallization of the anodic barrier oxide between the outer porous layer and the metal substrate, and (ii) the simultaneous preferential dissolution of the initially formed outer amorphous oxide [9].

To shed light on the growth mechanism of porous anodic $\mathrm{Nb}$ oxide in pure molten $\mathrm{o}-\mathrm{H}_{3} \mathrm{PO}_{4}$, we explored the effects of the anodization time on the structure of layers grown at $100^{\circ} \mathrm{C}$ and $40 \mathrm{~V}$. Top view and cross sectional SEM images of the resulting structures are shown in Fig. 6. The anodization times chosen to grow these structures are $15 \mathrm{~min}, 30 \mathrm{~min}$ and $1 \mathrm{~h}$ (indicated also by green symbols on the relative J-time characteristic in Fig. $4 \mathrm{a}$ - green curve).

After $15 \mathrm{~min}$ the anodic layer shows vertically aligned, $~ 10 \mathrm{~nm}$ wide nanochannels separated from the metal substrate by a $\sim 80-90 \mathrm{~nm}$ thick barrier oxide (Fig. $6-15 \mathrm{~min}$ ). At this point the anodic current density is $\sim 0.5 \mathrm{~mA} \mathrm{~cm}^{-2}$.

After $30 \mathrm{~min}$, the pore openings at the layer surface slightly widen, and the nanochannels seem to lose partly their vertical alignment, forming at the topmost part of the oxide layer a "fishbone" structure. The most relevant morphological changes take place near the oxide/metal interface (Fig. 6-30 min). Here one can observe the incipient formation of pores with an average inner diameter of $\sim 100 \mathrm{~nm}$ and a u-shaped bottom. The $\sim 80-90 \mathrm{~nm}$ thick barrier oxide is preserved. Please note that this anodization time is slightly beyond the onset of current density increase shown in the J-time characteristic in Fig. 4a (green curve).

A further increase of the anodization time renders the pore morphology at the bottom of the anodic layer even more defined (Fig. $5-1 \mathrm{~h}$ ). The $\sim 80-90 \mathrm{~nm}$ thick barrier oxide remains unchanged. Moreover, at the anodic oxide top it is possible to see both the nanochannel structure as well as the underneath array of wider nanopores. At this point the anodic current density is $\sim 1$ 
$\mathrm{mA} \mathrm{cm}{ }^{-2}$ (see the J-time characteristic in Fig. 4a, green curve), i.e. is twice as much as that recorded at $15 \mathrm{~min}$.

Given the constant thickness of the barrier layer during the formation of the porous film, one can confirm the film to grow via a field-assisted dissolution mechanism, i.e. by a balance between the rate of oxide formation (presumably through inward migration of oxygen species to the metal/oxide interface), and dissolution at the pore base (due to the high electric field). We propose that under high field conditions, also a stress-induced flow of formed oxide from the pore base to the walls is likely to occur [21].

Scheme 1 illustrates the morphology developed by the anodic oxide at different voltages. Based on the results outlined above, we propose that different oxide structures develop depending on the applied field strength as follows:

Low field: The anodic growth at a low applied field (voltages in the $2.5-5 \mathrm{~V}$ range) leads to vertically aligned, defined nanochannel layers. Given the relatively low steady state current density $\left(\sim 0.25 \mathrm{~mA} \mathrm{~cm}^{-2}\right)$, no significant morphological change in the anodic oxide is observed with increasing anodization time. The layer thickness depends on the anodization time, and increases linearly up to $10 \mathrm{~h}$ with an average growth rate of $\sim 800 \mathrm{~nm} \mathrm{~h}-1$, as shown in our previous work [12]. This also suggest that low field conditions cause minimal dissolution of the anodic oxide formed (at least this is valid for short anodization times, e.g. $<10 \mathrm{~h}$ ).

Transition voltage region: Intermediate voltages $(10-20 \mathrm{~V})$ lead to lower pore ordering and less defined oxide morphology ("fish bone" structure) as ascribed to the higher current density ( 0.5 $\mathrm{mA} \mathrm{cm}^{-2}$ ). Consequently, the dissolution of the porous oxide layers is evident also for short anodization times (e.g. 1 h). These conditions are at the boundary between low and high field growth regimes. 
High field: Under high field conditions (voltages in the 40-60 V range), we observe for a sufficiently long anodization time ( $\geq 30 \mathrm{~min})$ the formation of a partially crystalline orthorhombic $\mathrm{Nb}_{2} \mathrm{O}_{5}$ hierarchical structure. $\mathrm{Ca} .10 \mathrm{~nm}$ wide nanochannels form within the first minutes of anodization. The gradual increase of current density (up to $\sim 1-2 \mathrm{~mA} \mathrm{~cm}^{-2}$ ) during anodization causes a partial crystallization of the anodic oxide at the oxide/metal interface (i.e. the barrier oxide). We propose that during the anodic growth, the crystalline oxide is incorporated in the porous layer (due to stress-induced oxide flow). Thus, wider nanopores form as their walls incorporate crystalline oxide and become hence more stable in the anodizing environment even at relatively high current densities, while the amorphous side nanochannels undergo gradual dissolution. The field crystallization is accelerated at increased formation voltages, i.e. higher than $40 \mathrm{~V}$, and may also be triggered by the high electrolyte temperatures (see below) or localized heating effects associated to "sparking" or breakdown events. These may be the cause of the current spikes observed in the J-time characteristics when anodizing at high voltage (60 V; Fig. 4a) or high temperature $\left(\geq 100^{\circ} \mathrm{C}\right.$; Fig. 8a).

Similar results were reported also for porous $\mathrm{Nb}$ [22] or $\mathrm{Ti}$ [23-25] anodic oxides grown in hot glycerol-phosphate electrolytes, where different oxide morphologies and degrees of self-ordering were developed depending on crucial anodizing parameters such as applied voltage (or anodizing current) and electrolyte temperature. A comparable transition from aligned nanochannels to fishbone structures was reported for anodic $\mathrm{TiO}_{2}$ layers, while partial crystallization was observed for both as-grown $\mathrm{Nb}$ and $\mathrm{Ti}$ oxides, probably due the high field applied or high electrolyte temperature. Moreover, partial crystallization and field strength dependence of the layer morphology was also reported for anodic porous Fe oxides by Habazaki and co-workers $[21,26,27]$. The electrolyte water content was proven a key parameter affecting both composition and morphology of the anodic oxide films. 
We furthermore explored the effect of the electrolyte temperature $\left(60-120^{\circ} \mathrm{C}\right)$ on the structure of anodic $\mathrm{Nb}$ oxide layers grown in pure, molten $\mathrm{o}-\mathrm{H}_{3} \mathrm{PO}_{4}$ at $40 \mathrm{~V}$ (anodization time: $1 \mathrm{~h}$ ). Top view and cross-sectional SEM images of the resulting structures are shown in Fig. 7 and 8, while the J$\mathrm{V}$ curves, and porous anodic layer and barrier oxide thickness for these anodic layers are compiled in Fig. 9.

The SEM images (Fig. 7 and 8) show that nanoporous $\mathrm{Nb}$ oxide layers can be grown at $40 \mathrm{~V}$ in the $60-110^{\circ} \mathrm{C}$ temperature range, and the porous anodic layer and barrier oxide thickness increases with increasing the electrolyte temperature (Fig. 9b,c). At $120^{\circ} \mathrm{C}$, the current density increased to $\sim 1 \mathrm{~A} \mathrm{~cm}^{-2}$ in a few seconds right after applying the anodic bias (not shown) and the experiment was therefore immediately interrupted: this only led to a $\sim 70 \mathrm{~nm}$ thick oxide layer, probably due to strong chemical dissolution of the anodic layer during the anodization.

Interestingly, when screening the $\mathrm{o}-\mathrm{H}_{3} \mathrm{PO}_{4}$ temperature from $60^{\circ} \mathrm{C}$ to $110^{\circ} \mathrm{C}$, we observed effects similar to those seen when increasing the anodizing voltage and hence the field strength (compare the anodic structures in Fig. 8 with those in Fig. 2 and 3). The J-V curves also show a comparable trend (compare data in Fig. 9a and Fig. 4a).

One can conclude that low voltages $(\leq 20 \mathrm{~V})$ or low temperatures $\left(\leq 90^{\circ} \mathrm{C}\right)$ lead to a low field anodic growth of amorphous arrays of $\mathrm{Nb}$ oxide nanochannels, featuring various degrees of selfordering. When high anodization temperatures and voltages are combined, high field conditions are established. At $40-60 \mathrm{~V}$ and $100-110^{\circ} \mathrm{C}$, the high-field causes (i) a gradual current density increase during the anodic growth, (ii) the consequent partial crystallization of the formed anodic porous oxide, and (iii) subsequent dissolution of the amorphous oxide nanochannels, leaving behind partially crystalline, $100 \mathrm{~nm}$ wide orthorhombic $\mathrm{Nb}_{2} \mathrm{O}_{5}$ nanopores. 


\section{Conclusions}

We explored the anodic oxidation of $\mathrm{Nb}$ in pure molten $\mathrm{o}-\mathrm{H}_{3} \mathrm{PO}_{4}$ by screening parameters such as the anodizing voltage, time and electrolyte temperature, and discuss the anodic growth mechanism. We show that nanoporous $\mathrm{Nb}$ oxide layers can be grown under a wide range of electrochemical conditions, i.e. at an applied potential of $2.5-60 \mathrm{~V}$ and in a $60-110^{\circ} \mathrm{C}$ temperature range. The morphology of the anodic layers as well as their chemical composition and crystallographic features are affected by the anodizing conditions. Key factors are the applied potential (field strength) and resulting anodic current density. Current density values below $\sim 0.5$ $\mathrm{mA} \mathrm{cm}$, as those reached under steady conditions when anodizing at $2.5-10 \mathrm{~V}$, lead to vertically aligned amorphous $\mathrm{Nb}$ oxide nanochannels with an average diameter of 5-10 nm. Higher current density values (enabled by applied voltages $\geq 40 \mathrm{~V}$ ) cause a partial crystallization of the anodic oxide with simultaneous dissolution of the oxide nanochannel structures, leaving behind $100 \mathrm{~nm}$ wide, partially crystalline orthorhombic $\mathrm{Nb}_{2} \mathrm{O}_{5}$ nanopores. The findings reported in the present study will be useful to control the growth of anodic porous films on niobium.

\section{Acknowledgements}

The authors would like to acknowledge the ERC, the DFG, and the DFG cluster of excellence "Engineering of Advanced Materials" for financial support. M.A. and P.S. thank Prof. Sachiko Ono and Prof. Hidetaka Asoh for valuable discussions. 


\section{References}

[1] K. Lee, A. Mazare, P. Schmuki, One-Dimensional Titanium Dioxide Nanomaterials: Nanotubes, Chem. Rev. 114 (2014) 9385-9454. https://doi.org/10.1021/cr500061m.

[2] Q. Lu, T. Hashimoto, P. Skeldon, G.E. Thompson, H. Habazaki, K. Shimizu, Nanoporous Anodic Niobium Oxide Formed in Phosphate/Glycerol Electrolyte, Electrochem. SolidState Lett. 8 (2005) B17-B20. https://doi.org/10.1149/1.1883865.

[3] I. Sieber, H. Hildebrand, A. Friedrich, P. Schmuki, Formation of self-organized niobium porous oxide on niobium, Electrochem. Commun. 7 (2005) 97-100. https://doi.org/10.1016/j.elecom.2004.11.012.

[4] J. Choi, J.H. Lim, S.C. Lee, J.H. Chang, K.J. Kim, M.A. Cho, Porous niobium oxide films prepared by anodization in HF/H3PO4, Electrochim. Acta. 51 (2006) 5502-5507. https://doi.org/10.1016/j.electacta.2006.02.024.

[5] W. Wei, K. Lee, S. Shaw, P. Schmuki, Anodic formation of high aspect ratio, self-ordered Nb2O5 nanotubes, Chem. Commun. 48 (2012) 4244. https://doi.org/10.1039/c2cc31007d.

[6] Q. Lu, G. Alcalá, P. Skeldon, G.. Thompson, M.. Graham, D. Masheder, K. Shimizu, H. Habazaki, Porous tantala and alumina films from non-thickness limited anodising in phosphate/glycerol electrolyte, Electrochim. Acta. 48 (2002) 37-42. https://doi.org/10.1016/S0013-4686(02)00545-5.

[7] B. Melody, The Non-Thickness-Limited Growth of Anodic Oxide Films on Valve Metals, Electrochem. Solid-State Lett. 1 (1999) 126. https://doi.org/10.1149/1.1390659.

[8] H. Habazaki, Y. Oikawa, K. Fushimi, Y. Aoki, K. Shimizu, P. Skeldon, G.E. Thompson, Importance of water content in formation of porous anodic niobium oxide films in hot phosphate-glycerol electrolyte, Electrochim. Acta. 54 (2009) 946-951. https://doi.org/10.1016/j.electacta.2008.08.031. 
[9] Y. Oikawa, T. Minami, H. Mayama, K. Tsujii, K. Fushimi, Y. Aoki, P. Skeldon, G.E. Thompson, H. Habazaki, Preparation of self-organized porous anodic niobium oxide microcones and their surface wettability, Acta Mater. 57 (2009) 3941-3946. https://doi.org/10.1016/j.actamat.2009.04.050.

[10] M. Altomare, O. Pfoch, A. Tighineanu, R. Kirchgeorg, K. Lee, E. Selli, P. Schmuki, Molten o $-\mathrm{H}<$ inf $>3</$ inf $>$ PO $<$ inf $>4</$ inf $>$ : A new electrolyte for the anodic synthesis of self-organized oxide structures - WO<inf $>3</$ inf $>$ nanochannel layers and others, J. Am. Chem. Soc. 137 (2015) 5646-5649. https://doi.org/10.1021/jacs.5b02104.

[11] K.K. Upadhyay, M. Altomare, S. Eugénio, P. Schmuki, T.M. Silva, M.F. Montemor, On the Supercapacitive Behaviour of Anodic Porous WO3-Based Negative Electrodes, Electrochim. Acta. 232 (2017) 192-201. https://doi.org/10.1016/j.electacta.2017.02.131.

[12] K.K. Upadhyay, G. Cha, H. Hildebrand, P. Schmuki, T.M. Silva, M.F. Montemor, M. Altomare, Capacitance response in an aqueous electrolyte of $\mathrm{Nb} 2 \mathrm{O} 5$ nanochannel layers anodically grown in pure molten o -H 3 PO 4, Electrochim. Acta. 281 (2018) 725-737. https://doi.org/10.1016/j.electacta.2018.06.014.

[13] Y. Oikawa, K. Fushimi, Y. Aoki, H. Habazaki, Growth of Porous Anodic Films on Niobium in Hot Phosphate-Glycerol Electrolyte, in: ECS Trans., ECS, 2008: pp. 345-351. https://doi.org/10.1149/1.2982574.

[14] S. Yang, H. Habazaki, T. Fujii, Y. Aoki, P. Skeldon, G.E. Thompson, Control of morphology and surface wettability of anodic niobium oxide microcones formed in hot phosphate-glycerol electrolytes, Electrochim. Acta. 56 (2011) 7446-7453. https://doi.org/10.1016/j.electacta.2011.07.005.

[15] G.C. Wood, P. Skeldon, E. Thompson, K. Shimizu, A Model for the Incorporation of Electrolyte Species into Anodic Alumina, J. Electrochem. Soc. 143 (1996) 74. 
https://doi.org/10.1149/1.1836389.

[16] H. Hashimoto, Y. Shigehara, S. Ono, H. Asoh, Heat-induced structural transformations of anodic porous alumina formed in phosphoric acid, Microporous Mesoporous Mater. 265 (2018) 77-83. https://doi.org/10.1016/j.micromeso.2018.01.008.

[17] S. Ono, N. Masuko, The duplex structure of cell walls of porous anodic films formed on aluminum, Corros. Sci. 33 (1992) 503-507. https://doi.org/10.1016/0010-938X(92)90078H.

[18] S. Ono, N. Masuko, Effect of Electric Field Strength on Cell Morphology and Anion Incorporation of Anodic Porous Alumina, ECS Trans. 75 (2017) 23-31. https://doi.org/10.1149/07527.0023ecst.

[19] Q. Lu, S. Mato, P. Skeldon, G.. Thompson, D. Masheder, H. Habazaki, K. Shimizu, Anodic film growth on tantalum in dilute phosphoric acid solution at 20 and $85^{\circ} \mathrm{C}$, Electrochim. Acta. 47 (2002) 2761-2767. https://doi.org/10.1016/S0013-4686(02)00141$\mathrm{X}$.

[20] N. Liu, H. Mirabolghasemi, K. Lee, S.P. Albu, A. Tighineanu, M. Altomare, P. Schmuki, Anodic TiO2 nanotubes: double walled vs. single walled, Faraday Discuss. 164 (2013) 107-116. https://doi.org/10.1039/c3fd00020f.

[21] H. Habazaki, K. Shahzad, T. Hiraga, E. Tsuji, Y. Aoki, Formation of Self-Organized Porous Anodic Films on Iron and Stainless Steels, ECS Trans. 69 (2015) 211-223. https://doi.org/10.1149/06902.0211ecst.

[22] K. Lee, Y. Yang, M. Yang, P. Schmuki, Formation of Highly Ordered Nanochannel Nb Oxide by Self-Organizing Anodization, Chem. - A Eur. J. 18 (2012) 9521-9524. https://doi.org/10.1002/chem.201201426.

[23] D. Kim, K. Lee, P. Roy, B.I. Birajdar, E. Spiecker, P. Schmuki, Formation of a Non- 
Thickness-Limited Titanium Dioxide Mesosponge and its Use in Dye-Sensitized Solar Cells, Angew. Chemie. 121 (2009) 9490-9493. https://doi.org/10.1002/ange.200904455.

[24] K. Lee, D. Kim, P. Roy, I. Paramasivam, B.I. Birajdar, E. Spiecker, P. Schmuki, Anodic Formation of Thick Anatase TiO 2 Mesosponge Layers for High-Efficiency

Photocatalysis, J. Am. Chem. Soc. 132 (2010) 1478-1479.

https://doi.org/10.1021/ja910045x.

[25] K. Lee, D. Kim, P. Schmuki, Highly self-ordered nanochannel TiO2 structures by anodization in a hot glycerol electrolyte, Chem. Commun. 47 (2011) 5789. https://doi.org/10.1039/c1cc11160d.

[26] H. Habazaki, Y. Konno, Y. Aoki, P. Skeldon, G.E. Thompson, Galvanostatic Growth of Nanoporous Anodic Films on Iron in Ammonium Fluoride-Ethylene Glycol Electrolytes with Different Water Contents, J. Phys. Chem. C. 114 (2010) 18853-18859. https://doi.org/10.1021/jp1078136.

[27] K. Shahzad, E. Tsuji, Y. Aoki, S. Nagata, H. Habazaki, Formation and field-assisted dissolution of anodic films on iron in fluoride-containing organic electrolyte, Electrochim. Acta. 151 (2015) 363-369. https://doi.org/10.1016/j.electacta.2014.10.132. 


\section{Figure Captions}

Figure 1 Top view SEM images of anodic $\mathrm{Nb}$ oxide layers formed in pure o- $\mathrm{H}_{3} \mathrm{PO}_{4}$, at $100^{\circ} \mathrm{C}$, at different anodizing voltage $(2.5-60 \mathrm{~V}$ range; anodization time: $1 \mathrm{~h})$.

Figure 2 Cross sectional SEM images of anodic $\mathrm{Nb}$ oxide layers formed in pure $\mathrm{o}-\mathrm{H}_{3} \mathrm{PO}_{4}$, at $100^{\circ} \mathrm{C}$, at different anodizing voltage $(2.5-60 \mathrm{~V}$ range; anodization time: $1 \mathrm{~h})$.

Figure 3 Cross sectional SEM images of the barrier oxide of anodic layers formed in pure o$\mathrm{H}_{3} \mathrm{PO}_{4}$, at $100^{\circ} \mathrm{C}$, at different anodizing voltage (2.5-60 V range; anodization time: $\left.1 \mathrm{~h}\right)$.

Figure 4 a) J-V curves, and b) anodic porous layer and c) barrier oxide thickness for structures formed in pure $\mathrm{o}-\mathrm{H}_{3} \mathrm{PO}_{4}$, at $100^{\circ} \mathrm{C}$, at different anodizing voltages (2.5-60 V range; anodization time: $1 \mathrm{~h}$ ). The green symbols on the green curve in a) indicate the anodization time for structures shown in Fig. 6.

Figure 5 a) XRD patterns and b) surface phosphorous content (determined by XPS analysis) for anodic layers formed in pure $\mathrm{o}-\mathrm{H}_{3} \mathrm{PO}_{4}$, at $100^{\circ} \mathrm{C}$, at different anodizing voltage (2.5-60 V range; anodization time: $1 \mathrm{~h})$.

Figure 6 Top view and cross-sectional SEM images of anodic Nb oxide layers formed in pure o$\mathrm{H}_{3} \mathrm{PO}_{4}$, at $40 \mathrm{~V}$, at $100^{\circ} \mathrm{C}$, for different anodization times (top to bottom: $15 \mathrm{~min}, 30 \mathrm{~min}$ and $1 \mathrm{~h}$ ). 
Scheme 1 Sketch illustrating the effect of the anodizing voltage on the structure of the anodic $\mathrm{Nb}$ oxide layers. The illustration depicts the morphology of the porous and barrier oxide layers near the metal/oxide interface, for structures formed in pure $\mathrm{o}-\mathrm{H}_{3} \mathrm{PO}_{4}$, at $100^{\circ} \mathrm{C}$, at different anodizing voltage (2.5-60 V range; anodization time: $1 \mathrm{~h})$.

Figure 7 Top view SEM images of anodic $\mathrm{Nb}$ oxide layers formed in pure $\mathrm{o}-\mathrm{H}_{3} \mathrm{PO}_{4}$, at $40 \mathrm{~V}$, at different electrolyte temperatures $\left(60-120^{\circ} \mathrm{C}\right.$ range; anodization time: $\left.1 \mathrm{~h}\right)$.

Figure 8 Cross sectional SEM images of anodic $\mathrm{Nb}$ oxide layers formed in pure $\mathrm{o}-\mathrm{H}_{3} \mathrm{PO}_{4}$, at 40 $\mathrm{V}$, at different electrolyte temperatures $\left(60-120^{\circ} \mathrm{C}\right.$ range; anodization time: $\left.1 \mathrm{~h}\right)$.

Figure 9 a) J-V curves, and b) anodic porous layer and c) barrier oxide thickness for structures formed in pure $\mathrm{o}-\mathrm{H}_{3} \mathrm{PO}_{4}$, at $40 \mathrm{~V}$, at different electrolyte temperatures $\left(60-120^{\circ} \mathrm{C}\right.$ range; anodization time: $1 \mathrm{~h})$. 
Figures

Figure 1

Scale bar $=100 \mathrm{~nm}$
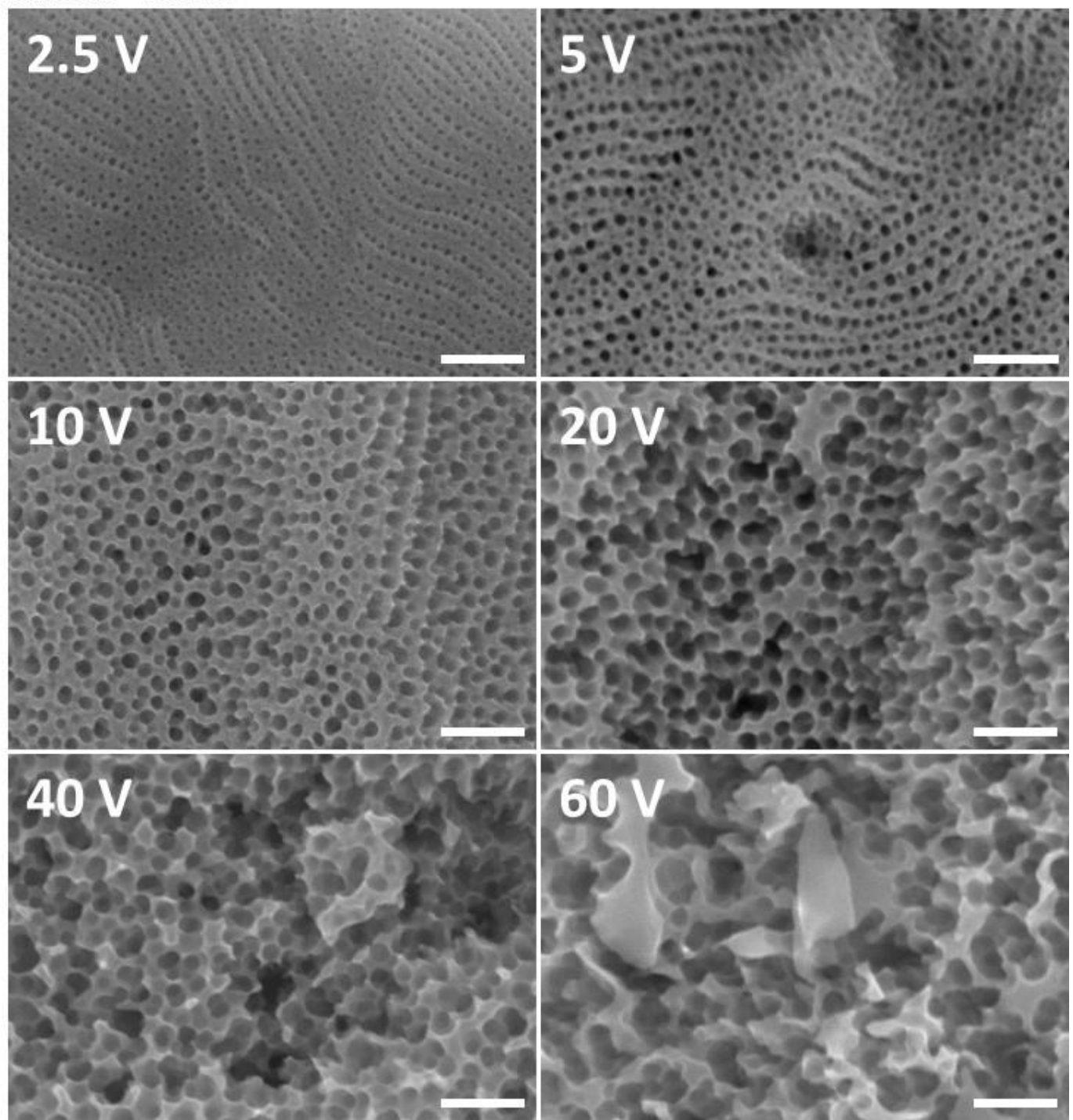
Figure 2

Scale bar $=100 \mathrm{~nm}$

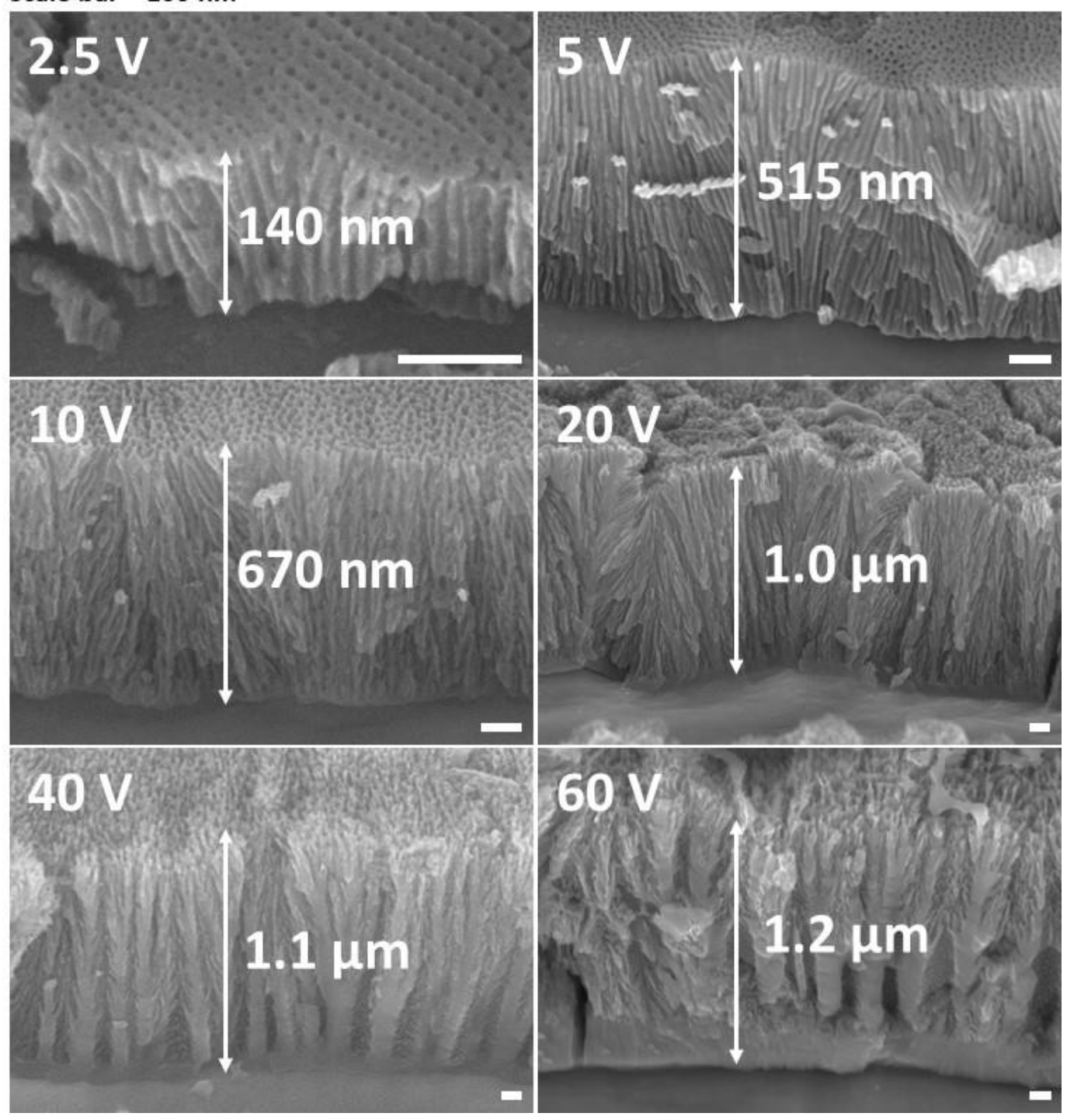


Figure 3

Scale bar $=100 \mathrm{~nm}$

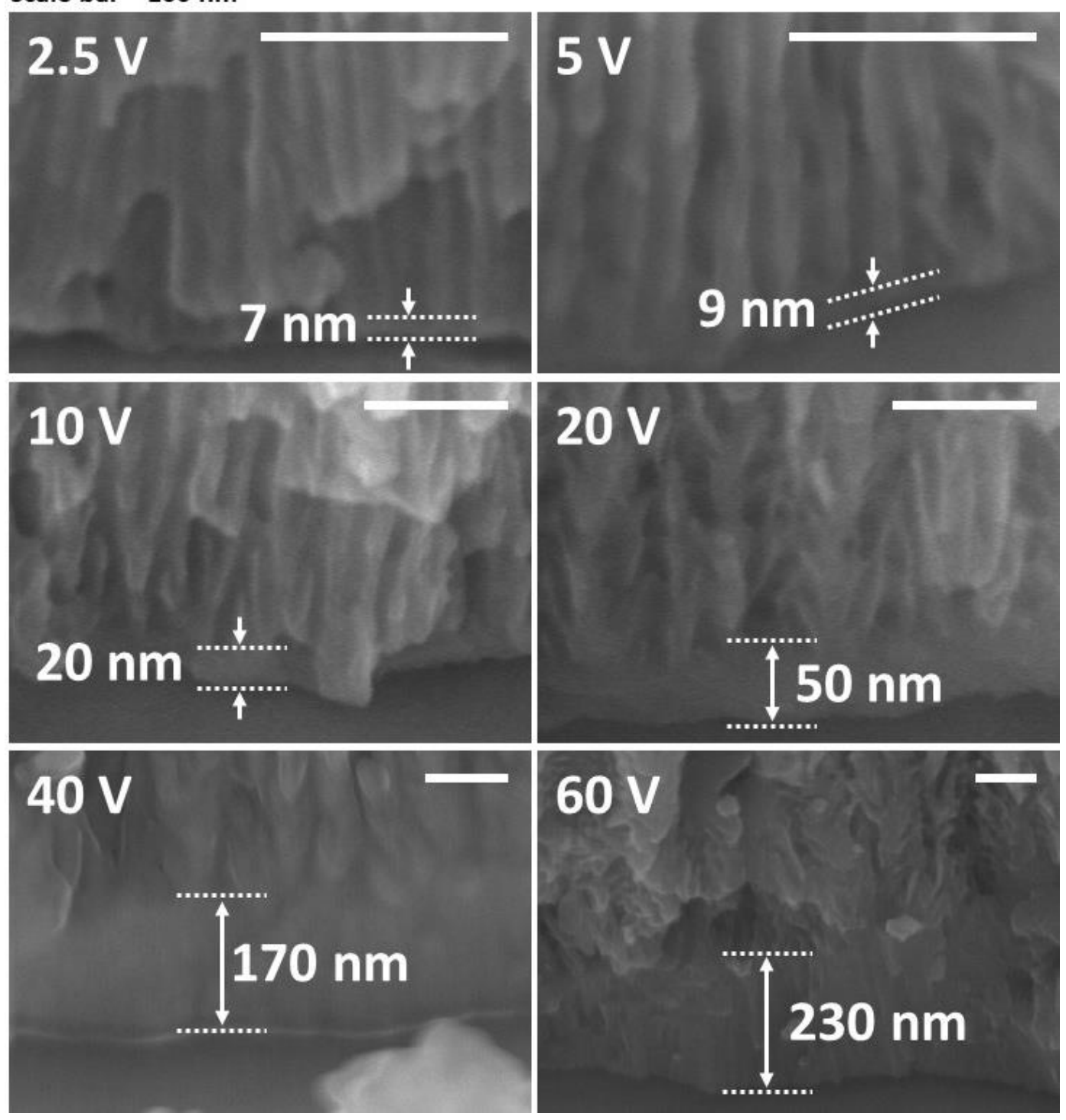


Figure 4
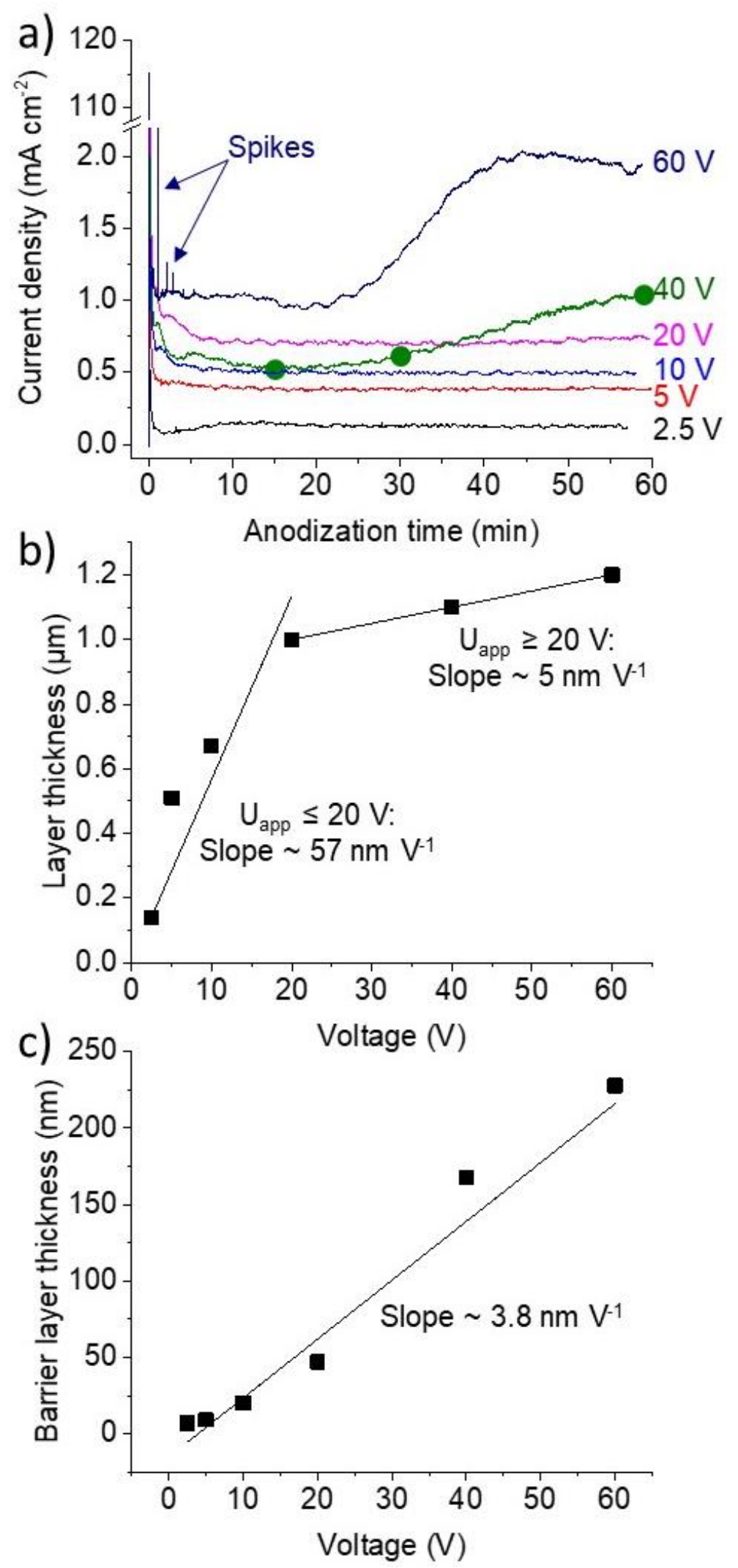
Figure 5
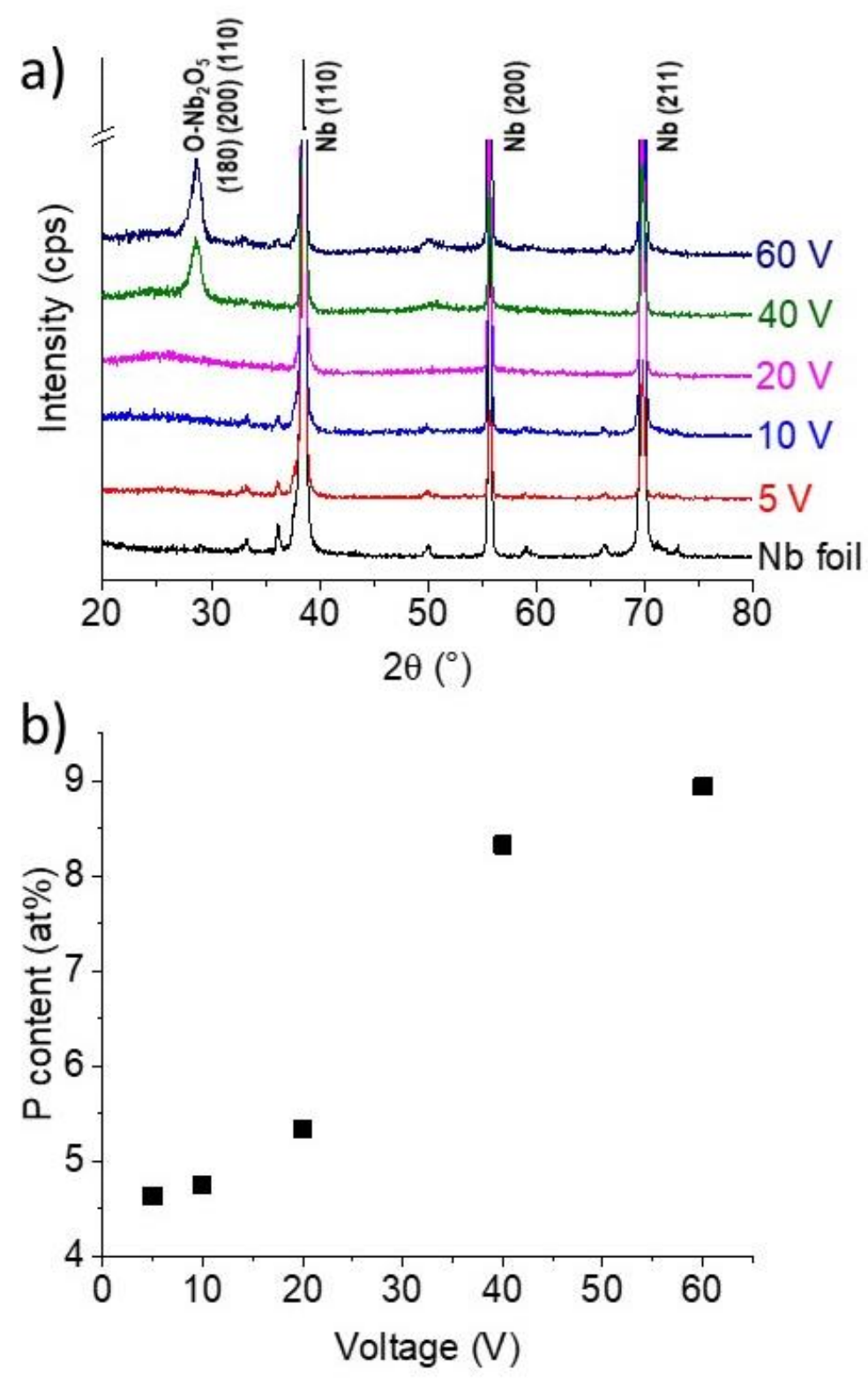
Figure 6

Scale bar $=100 \mathrm{~nm}$
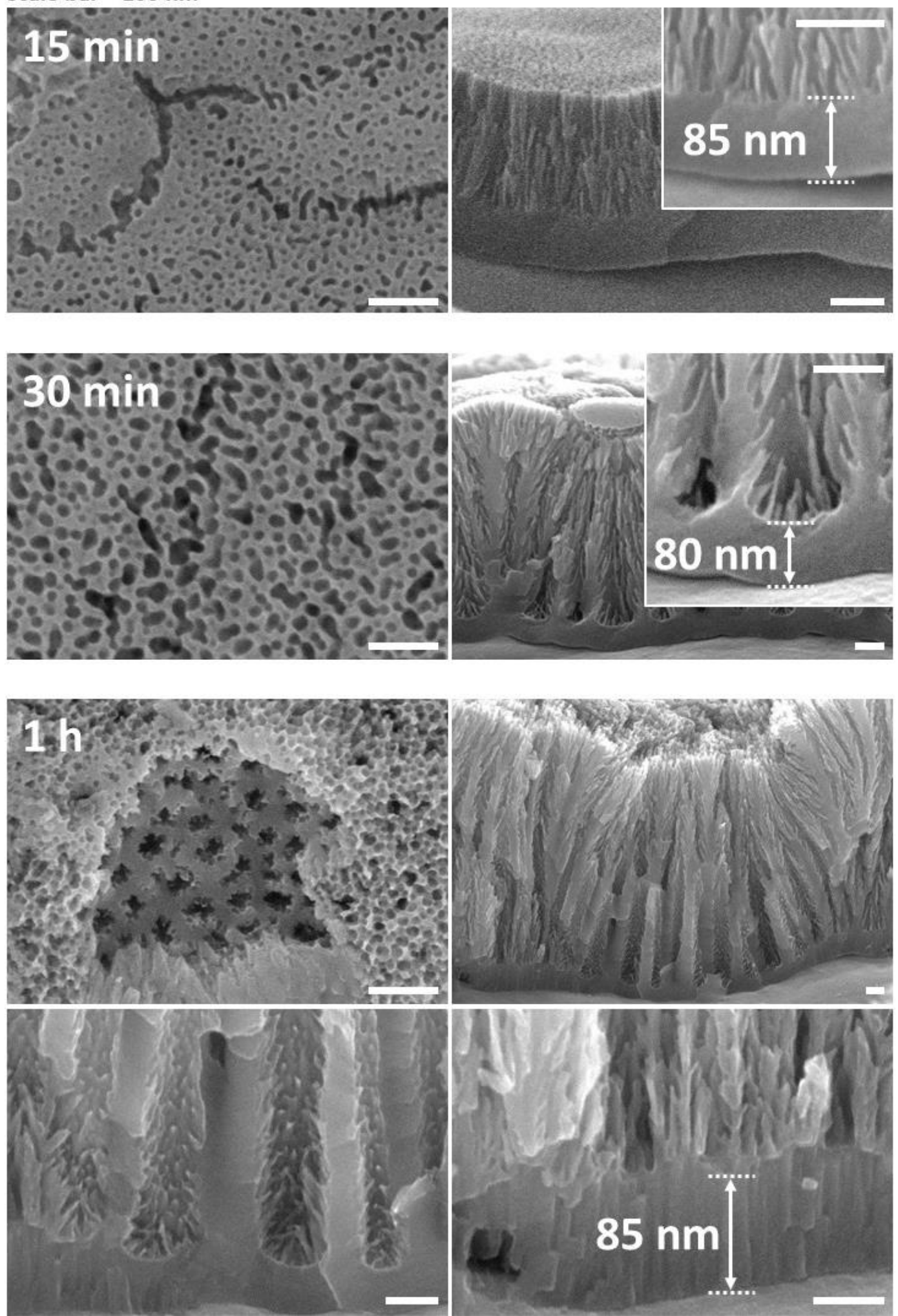


\section{Scheme 1}

$\leq 5 \mathrm{~V}$ : Vertically aligned nanochannels

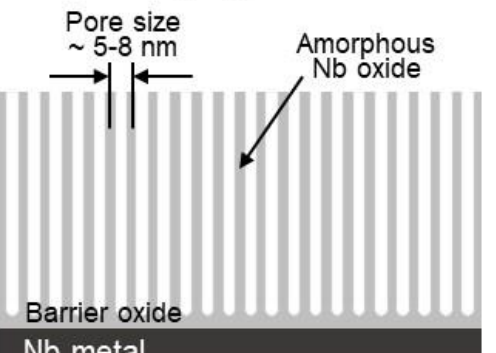

10-20 V: "Fish bone" structure

Pore size

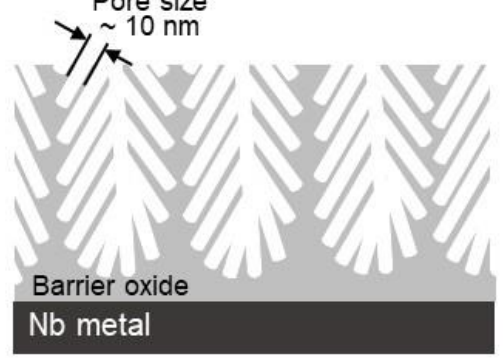

40-60 V: Nanopores

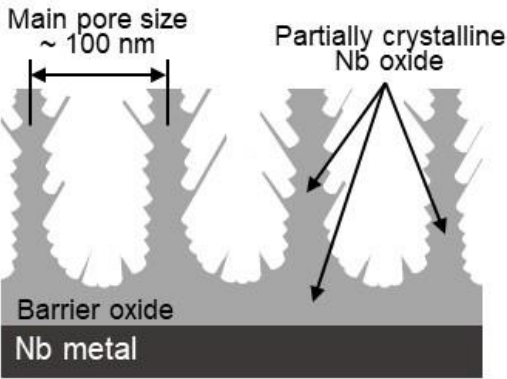

Increasing anodizing voltage and field strength 
Figure 7

Scale bar $=100 \mathrm{~nm}$

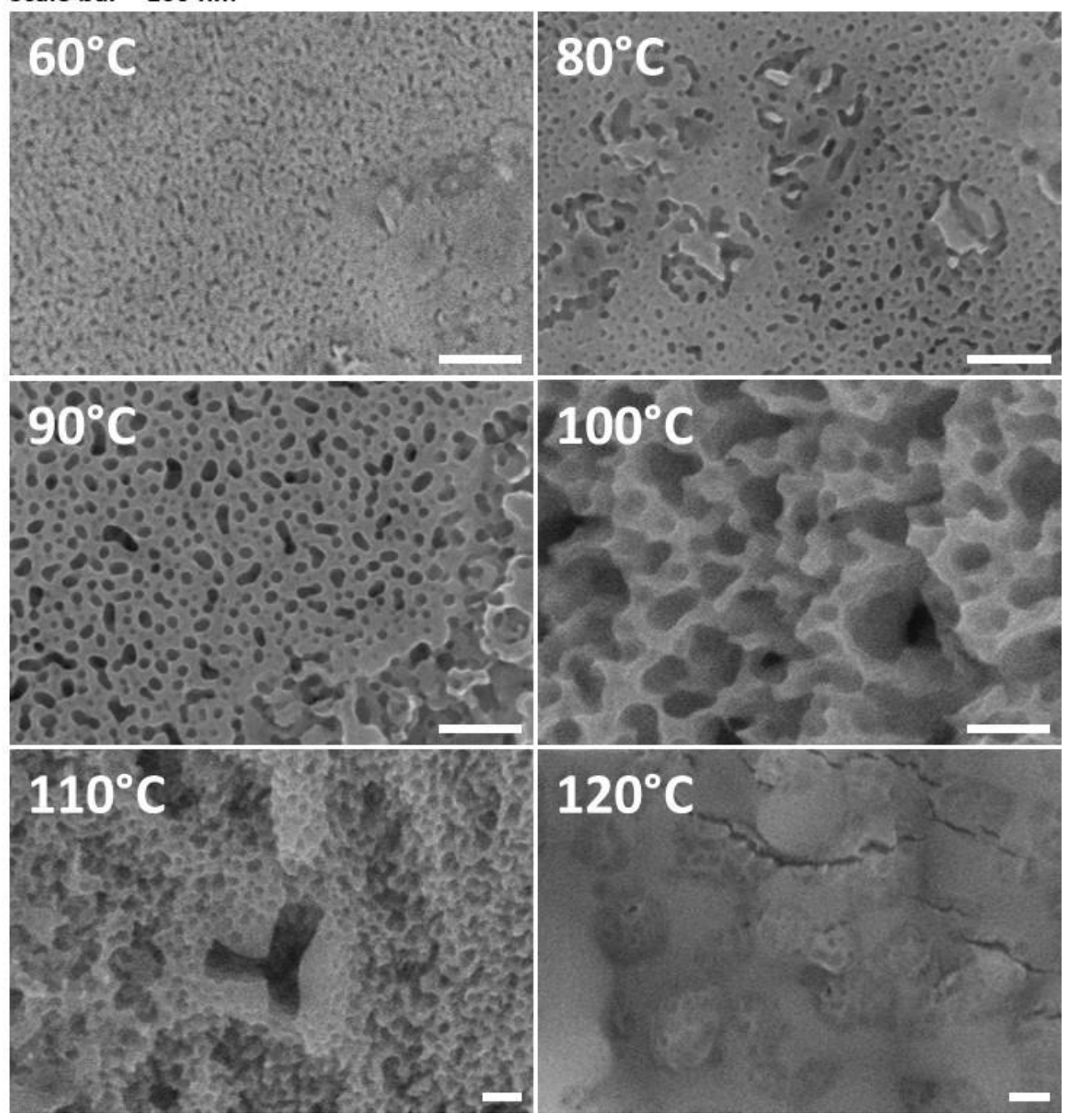


Figure 8

Scale bar $=100 \mathrm{~nm}$

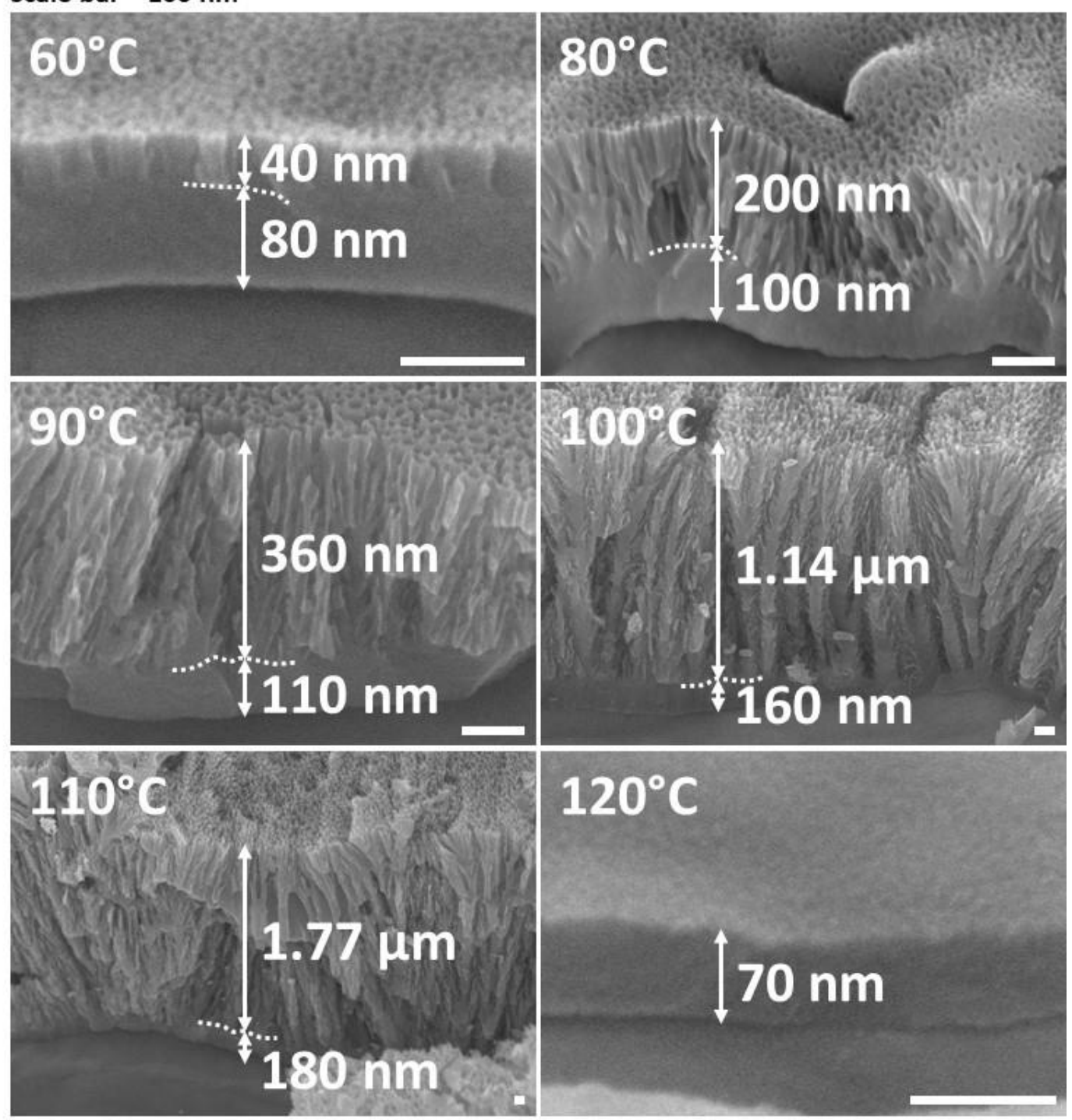


Figure 9
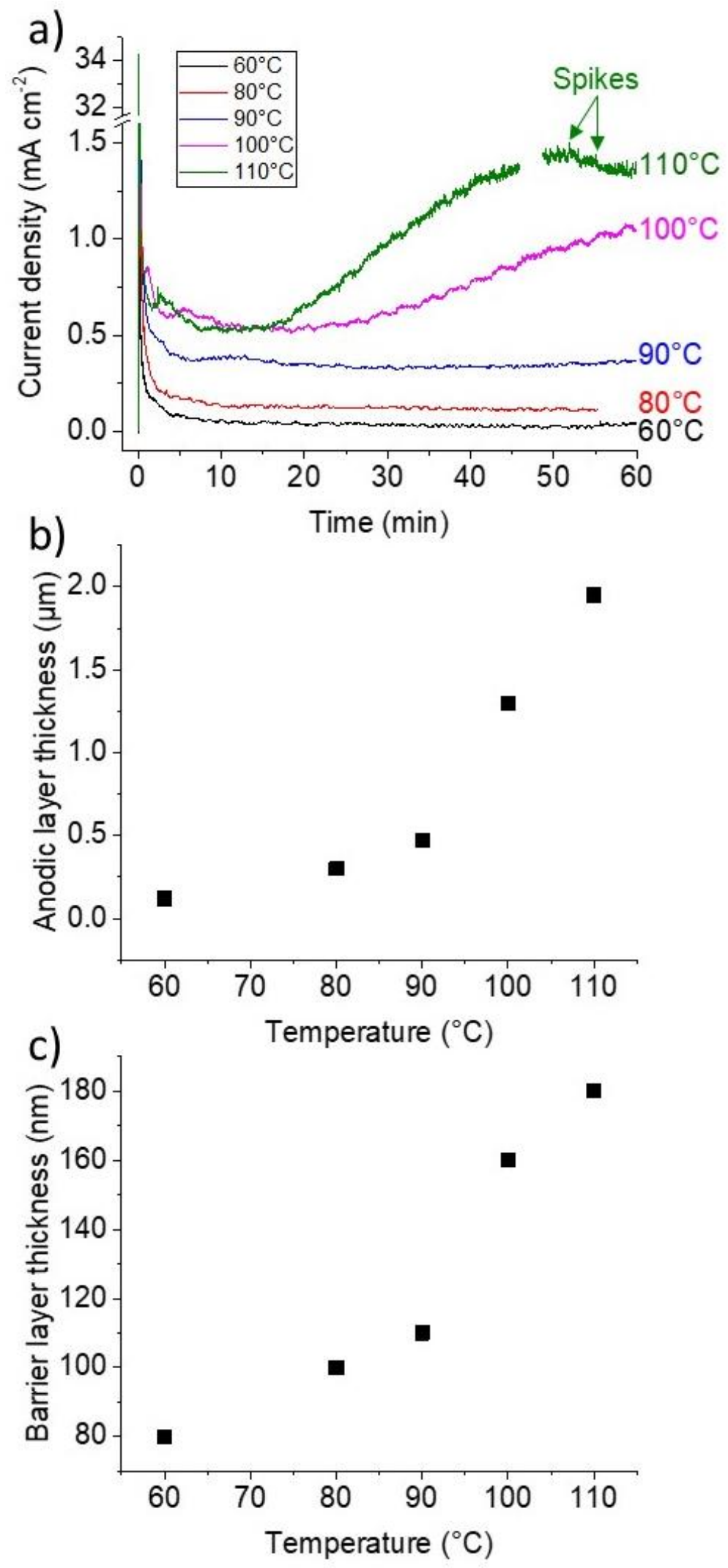